\title{
MTOR Inhibitor GDC-0349
}

National Cancer Institute

\section{Source}

National Cancer Institute. mTOR Inhibitor GDC-0349. NCI Thesaurus. Code C133227.

An orally bioavailable, ATP-competitive, tetrahydroquinazoline (THQ)-based inhibitor of the mammalian target of rapamycin (mTOR) with potential antineoplastic activity. Upon administration, GDC-0349 selectively binds to and inhibits the activity of mTOR, which may result in both the induction of tumor cell apoptosis and a decrease in tumor cell proliferation. mTOR, a serine/threonine kinase belong ing to the phosphatidylinositol-3 (PI3K) kinase-related kinase (PIKK) family, plays an important role in the PI3K/Akt/mT OR signaling pathway that regulates cell growth and proliferation, and its expression or activity is frequently dysregulated in human cancers. 